\title{
Correction to: Preoperative breast magnetic resonance imaging in patients with ductal carcinoma in situ: a systematic review for the European Commission Initiative on Breast Cancer (ECIBC)
}

\author{
Carlos Canelo-Aybar ${ }^{1,2}$ - Alvaro Taype-Rondan ${ }^{3}$. Jessica Hanae Zafra-Tanaka ${ }^{4}$. David Rigau ${ }^{2} \cdot$ Axel Graewingholt $^{5}$. \\ Annette Lebeau $^{6}$. Elsa Pérez Gómez ${ }^{7}$ Paolo Giorgi Rossi ${ }^{8} \cdot$ Miranda Langendam $^{9} \cdot$ Margarita Posso $^{2,10}$. \\ Elena Parmelli ${ }^{11}$ (1) $\cdot$ Zuleika Saz-Parkinson $^{11} \cdot$ Pablo Alonso-Coello ${ }^{1,2}$
}

Published online: 7 January 2022

(c) The Author(s) 2022

\section{Correction to: Eur Radiol (2021) 31:5880-5893 https://doi.org/10.1007/s00330-021-07873-2}

In this article the author name Miranda Langendam was incorrectly written as Miranda Langedam. The corrected author list is given above. The original article has been corrected.

Open Access This article is licensed under a Creative Commons Attribution 4.0 International License, which permits use, sharing, adaptation, distribution and reproduction in any medium or format, as long as you give appropriate credit to the original author(s) and the source, provide a link to the Creative Commons licence, and indicate if changes were made. The images or other third party material in this article are included in the article's Creative Commons licence, unless indicated otherwise in a credit line to the material. If material is not included in the article's Creative Commons licence and your intended use is not permitted by statutory regulation or exceeds the permitted use, you will need to obtain permission directly from the copyright holder. To view a copy of this licence, visit http://creativecommons. org/licenses/by/4.0/.

Publisher's note Springer Nature remains neutral with regard to jurisdictional claims in published maps and institutional affiliations.
The original article can be found online at https://doi.org/10.1007/ s00330-021-07873-2.

\section{Elena Parmelli}

Elena.Parmelli@ec.europa.eu

1 CIBER de Epidemiología y Salud Pública (CIBERESP), Madrid, Spain

2 Iberoamerican Cochrane Centre - Department of Clinical Epidemiology and Public Health, Biomedical Research Institute Sant Pau (IIB Sant Pau), Sant Antonio María Claret 167, 08025 Barcelona, Spain

3 Universidad San Ignacio de Loyola, Unidad de Investigación para la Generación y Síntesis de Evidencias en Salud, Lima, Peru

4 CRONICAS Centre of Excellence in Chronic Diseases, Universidad Peruana Cayetano Heredia, Lima, Peru

5 Radiologie am Theater, Paderborn, Germany
6 Institute of Pathology, University Medical Center Hamburg-Eppendorf, Hamburg, Germany

7 University Hospital Dr. Josep Trueta, Girona, Spain

8 Epidemiology Unit, Azienda USL - IRCCS di Reggio Emilia, Reggio Emilia, Italy

9 Department of Epidemiology and Data Science, Amsterdam UMC, University of Amsterdam, Amsterdam Public Health Institute, Amsterdam, Netherlands

10 Department of Epidemiology and Evaluation, IMIM (Hospital del Mar Medical Research Institute), Barcelona, Spain

11 European Commission, Joint Research Centre (JRC), Via E. Fermi, 2749. TP127, I-21027 Ispra, VA, Italy 